\title{
You mob my owl, I'll mob yours: birds play tit-for-tat game
}

\section{SUBJECT AREAS: \\ ZOOLOGY \\ ANIMAL BEHAVIOUR \\ ECOLOGY \\ EVOLUTION}

Received

30 July 2012

Accepted

9 October 2012

Published

12 November 2012

Correspondence and requests for materials should be addressed to I.K. (indrikis.krams@ut.

ee)

\author{
Tatjana Krama', Jolanta Vrublevska', Todd M. Freeberg ${ }^{2}$, Cecilia Kullberg ${ }^{3}$, Markus J. Rantala ${ }^{4}$ \\ \& Indrikis Krams ${ }^{5}$
}

'Institute of Systematic Biology, University of Daugavpils, LV-540 1 Daugavpils, Latvia, ${ }^{2}$ Department of Psychology and Department of Ecology and Evolutionary Biology, University of Tennessee, Knoxville, USA, ${ }^{3}$ Department of Zoology, Stockholm University, SE10691 Stockholm, Sweden, ${ }^{4}$ Department of Biology, University of Turku, FIN-20024 Turku, Finland, ${ }^{5}$ Institute of Ecology and Earth Sciences, University of Tartu, 51014 Tartu, Estonia.

Reciprocity is fundamental to cooperative behaviour and has been verified in theoretical models. However, there is still limited experimental evidence for reciprocity in non-primate species. Our results more decisively clarify that reciprocity with a tit-for-tat enforcement strategy can occur among breeding pied flycatchers Ficedula hypoleuca separate from considerations of byproduct mutualism. Breeding pairs living in close proximity (20-24 $\mathrm{m}$ ) did exhibit byproduct mutualism and always assisted in mobbing regardless of their neighbours' prior actions. However, breeding pairs with distant neighbours (69-84 m) either assisted or refused to assist in mobbing a predatory owl based on whether or not the distant pair had previously helped them in their own nest defense against the predator. Clearly, these birds are aware of their specific spatial security context, remember their neighbours' prior behaviour, and choose a situation-specific strategic course of action, which could promote their longer-term security, a capacity previously thought unique to primates.

eciprocal altruism is a form of mutual co-operation ${ }^{1,2}$, in which one individual helps another and receives assistance itself in return some time later ${ }^{3-5}$. Various studies have evaluated the actions of multiple individuals simultaneously cooperating in behaviours known as mobbing or predator inspection, revealing the ability of animals to follow tit-for-tat strategy ${ }^{6-10}$ However, the mechanisms motivating individuals to cooperate, for example to repulse a predator, are still far from being well understood ${ }^{4,11}$. Doubts persist whether non-primate species possess the cognitive abilities to remember the outcome of previous interactions and accordingly to select future cooperators $^{4,12,13}$. Thus, a number of studies have suggested that animals' cooperative interactions are motivated only by short-term rewards based on byproduct mutualism or by the need to retain a valuable potential partner ${ }^{14}$. Cognitive skills may also constrain the ability of animals to establish and maintain reciprocity, which could explain why finding evidence for contingent reciprocity in nonhuman animals has been difficult ${ }^{15,16}$. However, some recent evidence suggests that animals are indeed capable of acting according to their future, rather than current, needs ${ }^{17-25}$.

Reciprocity denotes a behaviour whereby an organism acts in a manner such that it risks reducing or even losing its fitness while increasing the fitness of another organism, because this other organism is likely to act similarly at a later time $e^{2,17,26}$. The original analysis of the conditions where reciprocity could evolve suggested that organisms should follow simple strategies such as 'tit-for-tat', i.e. an initial bias towards cooperation, followed by each individual copying its counterpart's moves ${ }^{2,26}$. Previous experiments with pied flycatchers showed clear response patterns to assist "co-operating" in preference over "defecting" conspecific neighbours based on a prior event ${ }^{19,20,27}$, but there arose questions about byproduct mutualism and dominance effects because of the moderately close proximity of the nestboxes (48-54 m apart) ${ }^{18,24,28}$.

We carried out a field experiment to test whether breeding pied flycatchers can act purely reciprocally when mobbing in response to a predator. We tested this possibility against the hypothesis that the behaviour might be explicable in terms of byproduct mutualism, whereby the activities of an organism provide benefits predominantly for itself and only incidentally to others. We compared the mobbing responses of pied flycatchers for two proximity groups: those breeding either closely or distantly from one another.

\section{Results}

In the control subgroups, when an owl was presented at nestboxes \#1 of the 'close' pairs and the 'distant' pairs, adult flycatchers of both subgroups mobbed the predator (Fig. 1). This happened in all 12 cases in 'close' pairs control birds and in all 12 cases in 'distant' pairs control birds (Fisher's exact test, $\mathrm{P}=1.00$ ). When the owl was 
presented $1 \mathrm{hr}$ later at nestbox \#2, all of the previously assisted pairs of flycatchers from nestboxes \#1 for both 'close' and 'distant' groups reciprocated the assistance and arrived to mob the predator at the boxes of their cooperating neighbours (Fisher's exact test, $\mathrm{P}=$ $1.00)$.

In the experimental subgroups, nestbox \#1 birds in phase one had to mob the owl on their own, and were made aware of the "decision" of nestbox \#2 birds to defect. When the owl was presented $1 \mathrm{hr}$ later at nestbox \#2, all 12 defectors from nestbox \#2 were assisted by their 'close' neighbours, while only 2 out of 14 defectors were assisted by their 'distant' neighbours (Fig. 1). The other 12 birds from the 'distant' experimental subgroup pairs were seen to interrupt their feeding and were heard giving alarm calls. These behavioural responses suggest that the uncooperative neighbours of the defectors were indeed aware of the situation at their 'distant' neighbour's nestbox. The incidence of reciprocity in the experimental subgroup of 'close' neighbours differed significantly from that of the 'distant' group (Fisher's exact test, $\mathrm{P}=0.0001$ ).

\section{Discussion}

These results suggest that joining in the mobbing of predators at the nests of near-neighbours might contribute to the protection of one's own nest, and thus be explicable in terms of byproduct mutualism. It has been shown that a predator tends to leave an area sooner, the more intensely it is harassed ${ }^{29-32}$. It has also been shown that predators avoid visiting areas where they have been previously harassed ${ }^{29}$. Thus, prey individuals may profit from a joint defence against predators because their own fitness may be enhanced as a result of the generally reduced probability of predation.

Our results demonstrate that breeding pied flycatchers transition to cooperation behaviours which resemble reciprocity as the distance to a neighbour increases. For distant neighbours, they significantly punished defectors and reliably assisted cooperators. This finding suggests that they are aware of their spatial context, are aware of current and fully capable of remembering previous social interactions with neighbours, change their responses as a result of previous experiences, and choose a situation-specific strategic course of action which might promote their own (self-centered) longer-term security (fitness). This is a demonstration of tit-for-tat strategy, where only co-operating individuals will be supported by their neighbours in the next move. The choice of mobbing or defecting in the distant-neighbour group appears to be an instance of a prisoner's dilemma. Since harassment of a predator may entail a risk of injury or even death ${ }^{33-35}$ defection against a non-cooperating individual, rather than cooperation, may be the best option. To mob or not to mob - that is the question, and the answer for a pied flycatcher appears to be a reasonable pattern of responses which incorporates spatial, behavioural, historical, real-time, and future factors.

\section{Methods}

Study site and birds. The study was conducted in May and June 2010 and 2011 near Krāslava, southeastern Latvia $\left(55^{\circ} 90^{\prime} \mathrm{N}, 27^{\circ} 19^{\prime} \mathrm{E}\right)$. We placed nestboxes in pairs in pine forests with sparse understory, with pairs separated by at least $650 \mathrm{~m}$. 'Close' nestboxes were located 20-24 m from one another (mean $\pm \mathrm{SD}=22 \pm 0.96 \mathrm{~m} ; 24$ pairs of nestboxes) and 'distant' nestboxes 69-84 $\mathrm{m}$ from one another (mean $\pm \mathrm{SD}=$

\section{(A) 'Close' Pairs}

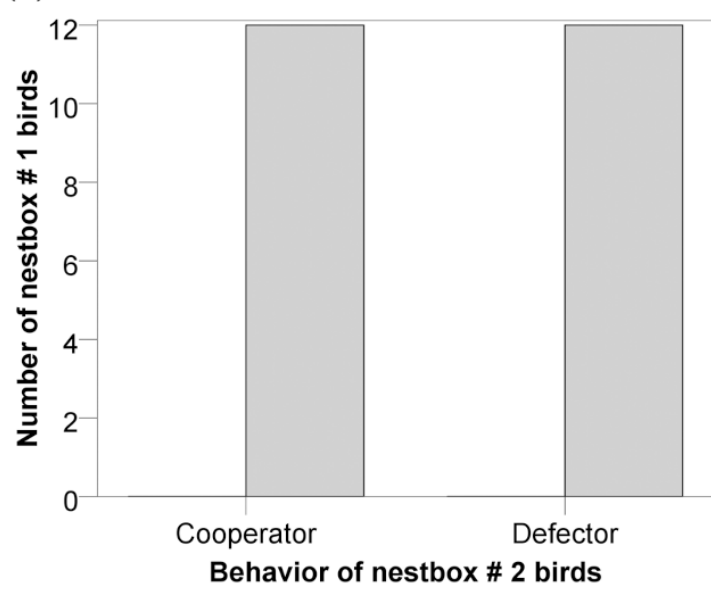

(B) 'Distant' Pairs

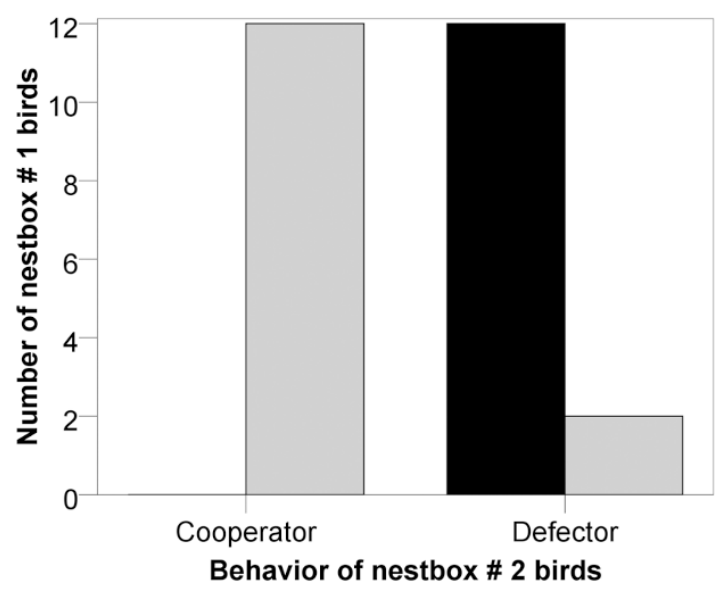

Pair \# 1 behavior

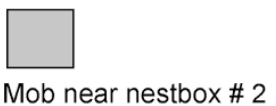

Remain at nest

Figure $1 \mid$ Number of pairs of pied flycatchers in 'close' and 'distant' groups that assisted co-operators, assisted defectors and remained at their own nest. 
$80.02 \pm 3.50 \mathrm{~m} ; 26$ pairs of nestboxes). 'Close' and 'distant' nestbox pairs were further assigned to either an experimental or a control subgroup. In the 'close' group, 12 pairs of nestboxes were assigned to the experimental and 12 to the control subgroup. In the 'distant' group the corresponding assignment was 14 pairs to the experimental and 12 pairs to the control subgroup.

Since parents should take higher risks while defending larger and older broods ${ }^{36,37}$, we included in the experiment only nests with $\geq 10$-day old nestlings, and with 6-7 chicks. The age of nestlings did not differ between the 'close' and 'distant' neighbour groups (2-tailed paired $\mathrm{t}$-test, $\mathrm{t}=-0.73, \mathrm{df}=49, \mathrm{P}=0.36$ ).

All adult flycatchers were marked with light colours of non-waterproof ink 2-4 days before the trials. The birds marked themselves by touching a piece of ink-saturated foam-rubber at the entrance of their nestboxes. We captured birds by temporarily modifying the nestbox entrance hole so that birds could enter, but not leave. Calls played back to ensure recognition of defection were recorded with a PCMD50 Solid State Recorder connected to a parabolic microphone.

We manipulated the owl stimulus and observed and evaluated flycatcher behaviour from a hide. The owl was mounted on a pole on a small platform $1.2 \mathrm{~m}$ above ground. It was installed when no pied flycatcher was detected nearby, and was positioned 1.0$1.5 \mathrm{~m}$ from the nestbox. The owl was looking towards the nest, being placed between two neighbouring nestboxes. Before presenting the owl to birds in the 'close' neighbour group, we kept the predator under cover. We uncovered and presented the predator only when the nest owners appeared in the vicinity, to exclude the possibility that neighbouring individuals could discover and start mobbing before mobbing was initiated by nest owners. Directly after each 15 -min period of presenting the owl, the stimulus was moved into the hide.

Predator presentation. For phase one in both 'close' and 'distant' experimental subgroups, during the nestling phase we presented a stuffed tawny owl Strix aluco, a common predator of small birds in Northern Europe, that was mounted on a pole on a small platform $1.2 \mathrm{~m}$ above ground, It was installed when no pied flycatcher was detected nearby, and was positioned 1.0-1.5 m from the nestbox. The owl was looking towards the nest, being placed between two neighbouring nestboxes ${ }^{19}$. While presenting the owl to birds in the 'close' neighbour group, we initially kept the predator under cover. We uncovered and presented the predator only when the nest owners appeared in the vicinity, to exclude the possibility that neighbour individuals could discover and start mobbing before mobbing was initiated by nest owners. Directly after each 15-min period of presenting the owl, the stimulus was moved into the hide.

In both experimental subgroups, just before the owl was exposed at nestbox \#1, we captured both parents breeding in nestbox \#2 and kept them in captivity (out of sight of the pair at nestbox \#1) for the 15 min of exposure of the owl at nestbox \#1. During these $15 \mathrm{~min}$, we played back alarm calls of pair \#2 recorded 4-6 days previously. As such, we made it clear to the nestbox \#1 pair that the \#2 pair was aware of a predator and had chosen to defect. Our previous results revealed that pied flycatchers generally remained near their own nests and made alarm calls when "retaliating" against neighbours which had recently defected from assisting them ${ }^{19}$. As soon as the predator was removed, we released the 'defectors'. In the control subgroups, when the owl was presented at nestbox \#1, the nestbox \#2 birds were left free to assist their neighbours.

For phase two, $1 \mathrm{hr}$ later, in both control and experimental subgroups, we presented the owl for $15 \mathrm{~min}$ at nestbox \#2 and monitored the behaviour of both the resident (\#2) and the neighbour pair (\#1). We expected that predators placed near one of the closely located pairs of nestboxes would represent an equal threat to both pairs of birds and that therefore both experimental and control pairs in the 'close' groups would join in the mobbing, whether or not their neighbours had assisted them previously. This is because mobbing alongside a defector is in the individual's interest given the proximity of the predator in the 'close' pairs. On the other hand, under the hypothesis of reciprocity, we predicted that flycatchers from pairs of distant nestboxes would join in mobbing only if their neighbours previously had assisted them. Thus, in the 'distant' group we predicted mobbing for control pairs, but no mobbing in experimental pairs.

The experiments comply with the current laws of the Republic of Latvia. All animal manipulations were approved by Latvian Council of Science (grant \# 09.1186).

1. Hamilton, W. D. The genetical evolution of social behaviour I and II. J. Theor. Biol. 7, 1-16, 17-32 (1964).

2. Trivers, R. L. Evolution of reciprocal alturism. Q. Rev. Biol. 46, 35-57 (1971).

3. Nowak, M. A. Five rules for the evolution of cooperation. Science 314, 1560-1563 (2006).

4. Raihani, N. J. \& Bshary, R. Resolving the iterated prisoner's dilemma: theory and reality. J. Evol. Biol. 24, 1628-1639 (2011).

5. West, S. A., Griffin, A. S. \& Gardner, A. Evolutionary explanations for cooperation. Curr. Biol. 17, R661-R672 (2007).

6. Milinski, M. Tit for tat in sticklebacks and the evolution of cooperation. Nature 325, 433-435 (1987)

7. Dugatkin, L. A. Do guppies play tit for tat during predator inspection visits? Behav. Ecol. Sociobiol. 23, 395-399 (1988).

8. Milinski, M., Külling, D. \& Kettler, R. Tit for Tat: sticklebacks (Gasterosteus aculeatus) "trusting" a cooperating partner. Behav. Ecol. 1, 7-11 (1990).

9. Dugatkin, L. A. Dynamics of the tit for tat strategy during predator inspection in the guppy (Poecilia reticulata). Behav. Ecol. Sociobiol. 29, 127-132 (1991).

10. Dugatkin, L. \& Alfieri, M. Interpopulational differences in the use of the Tit-ForTat strategy during predator inspection in the guppy, Poecilia reticulata. Evol. Ecol. 6, 519-526 (1992)
11. Bourke, A. F. G. Principles of social evolution. (Oxford University Press, 2011).

12. Stevens, J. R., Cushman, F. A. \& Hauser, M. D. Evolving the psychological mechanisms for cooperation in Annu. Rev. Ecol. Evol. Syst. 36, 499-518 (2005).

13. Melis, A. P. \& Semmann, D. How is human cooperation different? Philos. T. R. Soc B., 365, 2663-2674 (2010)

14. Nöe, R. \& Hammerstein, P. Biological markets: supply and demand determine the effect of partner choice in cooperation, mutualism and mating. Behav. Ecol. Sociobiol. 35, 1-11 (1994).

15. Stevens, J. R. \& Hauser, M. D. Why be nice? Psychological constraints on the evolution of cooperation. Trends Cogn. Sci. 8, 60-65 (2004).

16. Silk, J. B. Games primates play. Adv. Stud. Behav. 37, 1-41 (2007).

17. Wilkinson, G. S. Reciprocal food sharing in the vampire bats. Nature 308, 181-184 (1984).

18. Olendorf, R., Getty, T. \& Scribner, K. Cooperative nest defence in red-winged blackbirds: reciprocal altruism, kinship or by-product mutualism? Proc. R. Soc. Lond. B. 271, 177-182 (2004).

19. Krams, I., Krama, T., Igaune, K. \& Mand, R. Experimental evidence of reciprocal altruism in the pied flycatcher. Behavioral Behav. Ecol. Sociobiol. 62, 599-605 (2008).

20. Krams, I. et al. The increased risk of predation enhances cooperation. Proc. R. Soc. B.227, 513-518 (2010).

21. Melis, A. P., Hare, B. \& Tomasello, M. Do chimpanzees reciprocate received favours? Anim. Behav. 76, 951-962 (2008).

22. Cheke, L. G. \& Clayton, N. S. Eurasian jays (Garrulus glandarius) overcome their current desires to anticipate two distinct future needs and plan for them appropriately. Biol. Letters 8, 171-175 (2011).

23. Dufour, V., Wascher, C. A., Braun, A., Miller, R. \& Bugnyar, T. Corvids can decide if a future exchange is worth waiting for. Biol. Letters 8, 201-204 (2012).

24. Wheatcroft, D. J. \& Krams, I. Response to Russell and Wright: avian mobbing. Trends Ecol. Evol. 24, 5-6 (2009).

25. Seppänen, J. T., Forsman, J. T., Mönkkönen, M., Krams, I. \& Salmi, T. New behavioural trait adopted or rejected by observing heterospecific tutor fitness Proc. R. Soc. B. 278, 1736-1741 (2011).

26. Axelrod, R. \& Hamilton, W. D. The evolution of cooperation. Science 211, 1390-1396 (1981).

27. Krams, I., Krama, T. \& Igaune, K. Mobbing behaviour: reciprocity-based cooperation in breeding pied flycatcher Ficedula hypoleuca. Ibis 148, 50-54 (2006)

28. Russell, A. F. \& Wright, J. Avian mobbing: byproduct mutualism not reciprocal altruism. Trends Ecol. Evol. 24, 3-5 (2009).

29. Pavey, C. R. \& Smyth, A. K. Effects of avian mobbing on roost use and diet of powerful owls, Ninox strenua. Anim. Behav. 55, 313-318 (1998).

30. Robinson, S. K. Coloniality in the yellow-rumped cacique (Cacicus cela) as a defense against nest predators. Auk 102, 506-519 (1985).

31. Verbeek, N. A. M. Behavioural interactions between avian predators and their avian prey: play behaviour or mobbing? J. Comp. Ethol. 67, 204-214 (1985).

32. Krams, I., Berzins, A. \& Krama, T. Group effect in nest defence behaviour of breeding pied flycatchers, Ficedula hypoleuca. Anim. Behav. 77, 513-517 (2009).

33. Hoogland, J. L. \& Sherman, P. W. Advantages and disadvantages of Bank swallow (Riparia riparia) coloniality. Ecol. Monogr. 46, 33-58 (1976).

34. Curio, E. \& Regelmann, K. Predator harassment implies a real deadly risk: a reply to Hennessy. Ethol. 72, 75-78 (1986).

35. Poiani, A. \& Yorke, M. Predator harassment: more evidence on the deadly risk Ethol. 83, 167-169 (1989).

36. Curio, E. Brood defence in the great tit: the influence of age, number and quality of young. Ardea 75, 35-42 (1987).

37. Lambrechts, M. M. et al. Risk-taking restraints in a bird with reduced egg-hatching success. Proc. R. Soc. Lond. B. 267, 333-338 (2000).

\section{Acknowledgements}

T.K. and I.K. were supported by Science Council of Latvia. M.J.R. and I.K. received support from the Academy of Finland. European Social Fund within the project 'Support for the implementation of doctoral studies at Daugavpils University' Nr.2009/0140/1DP/1.1.2.1.2/ 09/IPIA/VIAA/015 supported Jolanta Vrublevska. Staffan Ulfstrand and Lennart Nilsson provided many useful comments.

\section{Author Contributions}

Experimental design by T.K., I.K. and M.J.R. Data collection conducted by T.K., J.V. and I.K. T.M.F., C.K. and I.K. analysed the data and wrote the manuscript. All authors discussed the results and provided comments on the manuscript.

\section{Additional information}

Competing financial interests: The authors declare no competing financial interests.

License: This work is licensed under a Creative Commons

Attribution-NonCommercial-NoDerivative Works 3.0 Unported License. To view a copy of this license, visit http://creativecommons.org/licenses/by-nc-nd/3.0/

How to cite this article: Krama, T. et al. You mob my owl, I'll mob yours: birds play tit-for-tat game. Sci. Rep. 2, 800; DOI:10.1038/srep00800 (2012). 